\title{
The NG-OSS Evolution of Telecom Service Providers: From Network-Focused to Customers-Focused
}

\author{
Lan Wang and Tingjie Lv \\ School of Economics and Management, Beijing University of Posts and \\ Telecommunications, Beijing 100876, P.R. China \\ wlan78@sina.com Tjl@public.bta.net.cn
}

\begin{abstract}
Now, the telecom service providers are faced with significant challenges as the traditional separated network and service become converged. Customers move to care more about the quality of service, such as the provision time, fault disposal, bill management, and security issues, other than networks. The carriers must integrate their core legacy mainframe operation support systems (OSS) with new generation components that can handle the requirements posed by new service offerings, which means the NG-OSS should pay attention to customers rather than networks. This paper examines the legacy OSS frame with its main component and analysis which part should be weakened or converged, and which part should be enhanced or updated. Then it suggests a more idealized view of a functional OSS architecture that conforms to the concepts of the TeleManagement Forum's Telecom Operations Map (TOM) model. In the last, it discusses how to evolve the OSS from the networkfocused to customers-focused successfully and smoothly.
\end{abstract}

Keywords: Operation support systems, OSS, Telecom service providers, Evolution

\section{INTRODUCTION}

OSS (Operations Support System) is a logical entity that represents a management system for telecom and networks. It comprises multiple functional blocks, usually, being called BSS/OSS in china. The traditional telecom support system includes: account system, service management system, customer service system and so on, such as "97 system" of China Telecom and China Unicom, custom server center and network management systems. With the development of the technology, nowadays, the telecom service providers are faced with significant challenges as the traditional separated network and service become converged. The legacy separated IT system can not meet the new service and customer's need. To solve these problems, the concepts of the TeleManagement Forum proposed the concept of Telecom Operations Map (TOM) model, with followed Enhanced Telecom Operations Map (eTOM). These now architectures involve integration of products with customized solutions. Based on the concept eTOM and the carriers' present procedures, this paper provides a operable BSS/OSS architecture and discussion of how to evolve the BSS/OSS from the network-focused to customers-focused successfully and smoothly.

Please use the following format when citing this chapter:

Wang, L., Lv, T., 2007, in IFIP International Federation for Information Processing, Volume 255, Research and Practical Issues of Enterprise Information Systems II Volume 2, eds. L. Xu, Tjoa A., Chaudhry S. (Boston: Springer), pp. $1207-1213$. 


\section{TECHNOLOGY AND BUSINESS DRIVING OF BSS/OSS SYSTEMS TRANSITION}

\subsection{Network Technology}

In the past 100 years, voice service is the center of the field of telecommunication. But now, the Communications carriers are faced with significant challenges as the transition from a Circuit Switched network to Packet Switching. Voice service becomes an application of internet; mobile service and broadband access service have been to the most important emphasis. Carriers move to deploy the next generation of broadband networks (NGN) based on IP/MPLS core network, which has the capable of delivering an array of services composed of voice, data, video, multimedia service, wire and wireless. With the technology of IMS V FMC, they can create a new enhanced offerings over a more converged, efficient, broadband enabled network. This transition will create new requirements on the entire CRM/BSS/OSS/NMS stack.

\subsection{Business Driving}

When the increasing speed of traditional telecom service slows down, group customer and new service are becoming new increasing revenue point of the carriers. BSS/OSS system can be used as a tool to arrive at the opportunities for increasing revenues and reducing costs by exploiting the un-utilized resources and improving operational\& organizational efficiency. So BSS/OSS will become the core competence capabilities of carriers.

"customer-focused" service architecture ask the current support systems to be transferred into the next generation support systems which aim to increase the levels of customer satisfaction, such as increase service delivery time, provide SLA reports. Analysis and correlation of these reports should provide the required insight to manage the network better.

What's more, in the competed telecommunication market, planning and forwarding of marketing have been the main method. The completed BSS/OSS systems can help in making decisions whether in terms of future expansions or strategic alliances, and IT process can also increase the efficiency of business activities.

The relationship between Network Technology and Business Driving can be shown as figure1.

\section{ARCHITECTURE AND DESIGN OF NG-OSS}

\subsection{The Problems of Legacy Systems}

Carriers may have as many as hundred systems in their BSS/OSS complex in one areas or province. The legacy BSS/OSS system can be divided three main parts: User 
interfaces, network operations, product management. A User interface often contains customer management system, Bill system. A network operation often contains NMS, EMS, resource management systems. A product management often contains wire-line service, wireless service, and internet service and so on. Typical dedicated systems that support specific process, which cause many problems, such as [1].

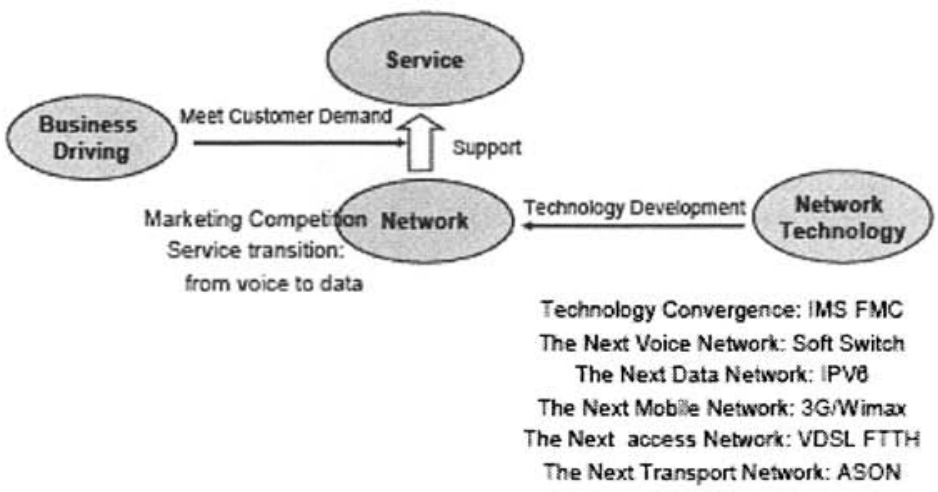

Figure 1. The Relationship between Network Technology and Business Driving

- Network operation can't meet the customer satisfaction. Lack of management capable of customers faced end to end services; it can't provide enhanced support for more direct customer control and personalization.

- The problems of multi-vendor supply of system components. Without a common way to manage all forms of the systems infrastructure, it's hard to integrate commodity by third party software into the system, and decrease the efficiency.

- Information and Data share. Customers information, product catalogue, network resource, such information is set in several separate system, It's hard to Establish common data schemas governed by common data stewardship with a common repository.

- IT systems can't support efficiently. The interface of several systems can't have a conversation automatically, lack of a common information bus infrastructure with associated models of interaction such as publish and subscribe, message exchange, broadcast, or transaction support.

These systems tend to have evolved over time in response to the slow introduction of new services and technology or in some case. 


\subsection{Customer-focused NG-OSS Model}

\subsubsection{Business Processes Design}

Well-defined business process aiming at end-customer satisfaction is a key to consideration of the next NG-OSS model. In the absence of good business framework, the spending towards operations increases affecting the profit. As the business process become defined to support the deployment of products for market segments within specific geographies, the business process in telecom can be listed as a circle management as figure 2 .

To begin with, the product management and customer relationship management (CRM) is the basic modules in these business process. Those process that work directly with customers and markets to define services (product) that will best meet the needs of their customers and provide competitive advantage. Then step into sale process which includes order management and resource management. Those process that work with orders and networks and arrange their network resource that will best meet the needs of their customers. The next step is accounting module that gives the revenue accounting of the product. Then, come back to marketing process. Marketing analysis system can be effectively utilized to generate reports based on products and networks. It can also serve as a tool to extrapolate financial figures based on the future plan of expansion as well as addition of new services. The last step maybe also the first step is customer relation management. So all these process are all focused in customers.

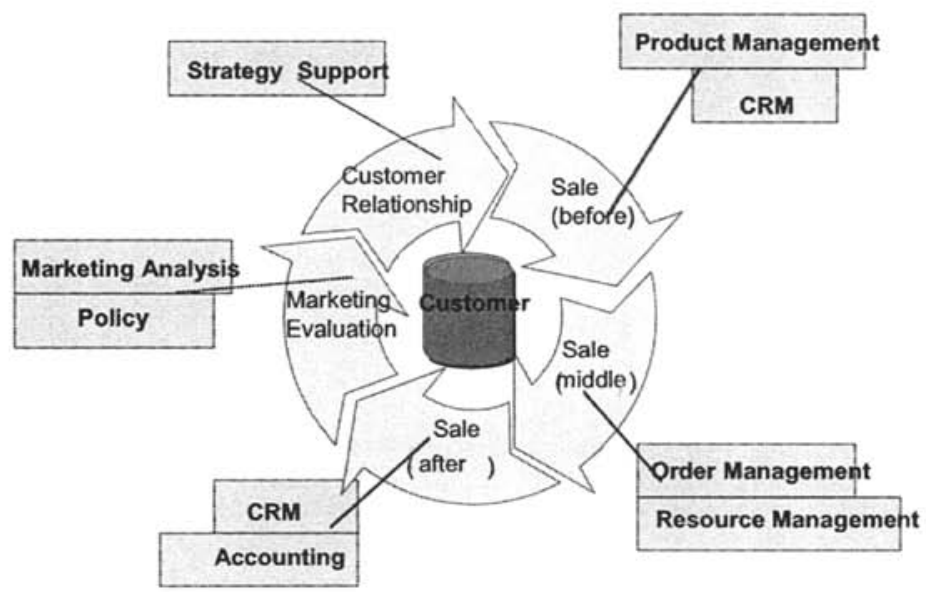

Figure 2. Business Processes in Telecom 


\subsubsection{BSS/OSS Model}

Telemanagement Forum has enhanced TOM to integrate the business processes with the logical block of integrated BSS/OSS[2-3]. This new model, called eTOM, effectively captures the complex business processes in a service provider's business. If the integration is modeled around eTOM, the service provider will be able to put robust business process framework in place helping him to gain better control over the business processes. This will have a direct impact on the revenues. ETOM focuses on two aspects:

- Business/ customer/ products

- Solution/ system/ implementation

Based on eTOM Model, the NG-OSS system architecture can be designed as fig. 3 .

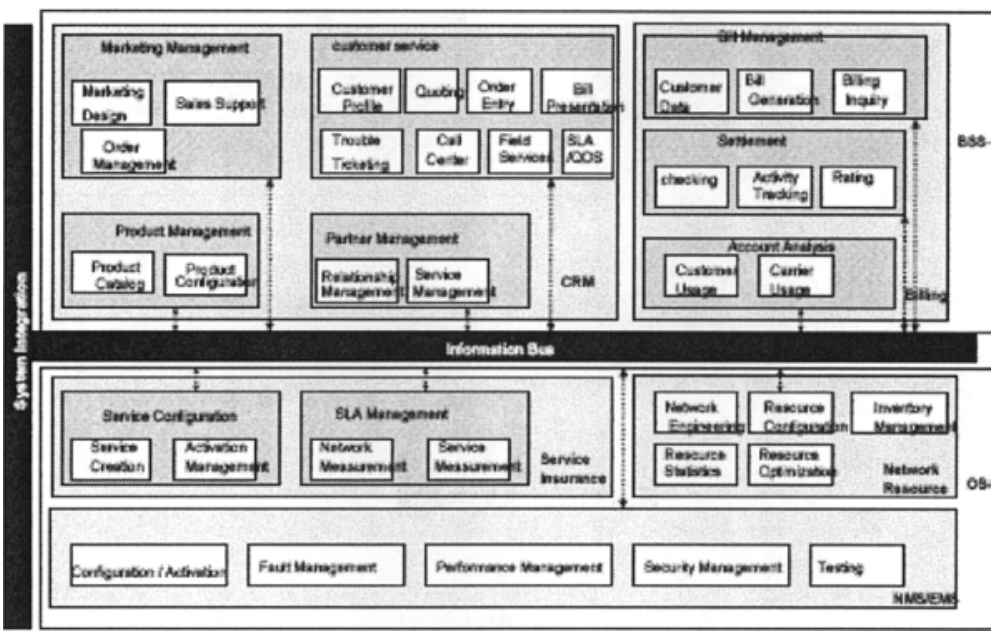

Figure 3. NG-OSS System Architecture

It includes two parts: BSS and OSS. BSS can be separated two sub parts which are CRM and Bill. OSS can be separated three parts which are service insurance and network resource management and the NMS \& EMS systems. The more details can be listed as follows:

- CRM: Marketing Management (marketing design/Sales Support/Order Management), Customer Service (Customer Profile/Quoting/Order Entry/Bill Presentation/ Trouble Ticketing/Call center/Field Service/SLA/QOS), Product Management (Product Catalog/Product configuration), Partner Management (Relationship Management/Service Management) - all these modules, which deal with the customer needs, ways to identify the needs and how to maintain and retain the relationship, aim to give the first class experience of customers.

- Billing: Bill Management (Customer Data/Bill Generation/Billing Inquiry), Settlement (checking, activity tracking, Rating), Account Analysis (Customer Usage, Carrier Usage) - all these modules provide reports to map revenue to the services. 
- Service Insurance: Service Configuration (Service Creation, Activation Management), SLA Management (Network Measurement, Service Measurement) - all these modules aim to make insurance of all services to customers.

- Network resource: Network Engineer, Resource Configuration, Inventory Management, Resource Statistics, Resource Optimization- all these modules would help in pre planning of the network update thus improving customer satisfaction.

- NMS/EMS: Configuration/Activation, Fault Management, Performance Management, Security Management, Testing__all these modules provide performance reports and fault management of the network whether it is fit to comply with SLA to customers.

- System integration: -Applications should be integrated that interact with each other in order to achieve a consolidated management view and functionality of the entire network and service.

- Information bus: - A common information bus infrastructure means associated models of interaction such as publish and subscribe, message exchange, broadcast, or transaction support.

\section{NG-OSS EVOLUTION STRATEGY AND CONCLUSION}

It's a huge project to complete all these BSS/OSS systems and should be divided into several steps. Here are some of the key steps that can be considered in NG-OSS evolution:

First: Getting ideas from the customer support team and making service development policy and route map.

Second: Analyzing situation/aim/value of business driving factors and their impact on systems.

Third: Summarizing the relationship between business driving and systems and making design of construction solutions.

Fourth: Deploying construction project, and evaluating.

Though there is a long way to step forward, but as mentioned above, with the implementation of right OSS/BSS applications and efficient business process framework modeled around eTOM, all the valuable information is available, which will give great valuable help to telecom service providers.

\section{REFERENCES}

1. Anonymous, Using NGOSS to Survive the Transition to Next Generation Networks, Cap Gemini Ernst \& Young (2001). http://www.tmforum.org/browse.aspx?catID=884 (Accessed April 6, 2007).

2. Satish Singla and Jyoti Shailendra, Making Right Decision Using OSS, Wipro Technologies, White Paper. http://www.wipro.com/whitepapers/services/telecomm_internetworking/oss.htm 
The NG-OSS Evolution of Telecom Service Providers: From Network-focused to Customers-focused 1213

(Accessed April 6, 2007).

3. Koteswara Rao Medida, Service Oriented Design and Architecture: Solving Telecom Systems Integration Problems, Wipro Technologies, White Paper.

http://www.wipro.com/webpages/insights/serviceorienteddesign.htm (Accessed April 6, 2007). 